\title{
HUMAN RIGHTS AND SEXUALITY - REIMAGINING THE LANGUAGE OF EQUALITY TOWARDS TRANSFORMATION IN AND THROUGH EDUCATION
}

\author{
A. de Wet \\ Research Unit for Education and Human Rights in Diversity (Edu-HRight) \\ Faculty of Education \\ North-West University \\ Potchefstroom, South Africa \\ e-mail: Annamagriet.dewet@nwu.ac.za
}

\section{ABSTRACT}

For many years, arguments in favour of sexual minorities' equality and sexuality rights have brought about legal reform worldwide. Although there are those who would contend that human rights and legal mechanisms associated with minorities could contribute to some positive experiences for sexual minorities, others have pointed out that legal reform brought about by the anti-discrimination laws does not necessarily result in a noticeable change in people's discriminatory attitudes, nor does it automatically translate into lived experiences of equity for minority groups. Research in the education sector shows that despite promises of inclusion and non-discrimination brought about by human rights law, many education institutions 'continue to reproduce patterns of heterosexism' (Francis and Msibi 2011, 160). Drawing from a project titled 'Human Rights Literacy: A search for meaning', the article explores how students in higher education institutions conceptualise sexual equality within a human rights discourse. Findings reported here indicate that the non-translation of legal rights into inclusion and equality for sexual minorities might be due to the gap between formal and substantive conceptualisations of equality. Acknowledgment of sexual minorities' equal rights appears to be superficial while students seemingly lack an awareness of the gap between formal equality and substantive equality and the inequalities that play out in this gap. Against the background of sexual minorities' unequal treatment and experiences, this article aims to re-imagine the language of equality towards equity for all sexualities in and through education.

Key words: sexual orientation, sexuality, equality, equity, heteronormativity, discrimination, human rights, transformation

\section{BACKGROUND}

For many years, arguments in favour of sexual minorities' equality and sexuality rights have brought about legal reform in several countries worldwide. In South Africa, the Constitution (SA, 1996) enshrines the right to equality, dignity and bodily integrity of all, including sexual minorities. Other legislation has been promulgated to protect these rights, such as the Promotion 
of Equality and Prevention of Unfair Discrimination Act which prohibits hate speech, and the Civil Union Act which provides for legal recognition of same-sex marriages. De Vos (2015b) contends that human rights and legal mechanisms associated with human rights could contribute to at least some positive experiences for sexual minorities. Yet, several authors point out that legal reform brought about by the anti-discrimination laws does not necessarily result in a noticeable change in people's discriminatory attitudes, nor does it automatically translate into lived experiences of equity for minority groups (De Vos 2015b; De Wet, Rothmann and Simmonds 2016; Becker, De Wet and Van Vollenhoven 2015).

Research in the education sector reveals that despite promises of inclusion and nondiscrimination brought about by human rights law, many education institutions 'continue to reproduce patterns of heterosexism' (Francis and Msibi 2011, 160). Reygan and Francis (2015) in particular highlights the pervasiveness of homophobic bullying in schools as well as the 'general unpreparedness of teachers to adequately address issues of gender and sexual diversity' as central concerns in education. The study by Francis and Msibi (2011) revealed that lesbian, gay, bi-sexual, transgender and queer/questioning (LGBTQ) youth experience discrimination in the form of prejudice, victimisation, harassment and physical violence in their education institutions, which is of particular interest given that research conducted by Allen in 2007 concluded that the daily rituals and routines inherent to a school's culture could result in sexual identities being assigned. When a school or other institution's culture is marked by heteronormativity and heterosexism, learners' sexualities could be positioned within the hierarchies and power relations of such a culture. Consequently, non-normative sexualities are positioned and subsequently oppressed as the 'deviant other' by affording privilege and benefits to members of the dominant group (heterosexual) and all who conform with or are assimilated into that group (Francis and Msibi 2011). Conformity and assimilation rather than diversity and uniqueness are rewarded, while non-conformity and being different are disciplined, thereby robbing sexual minorities of their freedom and ultimately creating unequal education environments.

Although teachers are in a position to challenge negative cultures and to promote equity, many avoid or ignore issues of sexual diversity when teaching sexual health (Francis 2012). Conversations about sexuality are avoided in favour of imagining learners as child-like and innocent rather than active sexual subjects (Allen 2007; Francis 2011). Even anti-oppressive teachers are reluctant to advocate against heterosexism because they fear controversy and conflict (Francis and Msibi 2011, 7) while some, on the ultimate downside, turn into perpetrators of sexual discrimination themselves (Francis and Msibi 2011). Teachers are key 
role-players in the constitutional project of transformation or, to quote Yacoob $(2016,1)$ : 'We are colleagues ... in making the vision of our constitution a reality'. However, as is evident from the findings Francis published in 2011 and 2015, despite legal, policy and curriculum commitments to sexual diversity and inclusivity, practice is still detached from policy due to uncertainty, ignorance and a lack of training.

Research in the first phase (2012-2014) of a project titled 'Human Rights Literacies: A quest for meaning' (Roux and Du Preez 2013) revealed that although student-teachers recognise the right to equality as a legal right, their heterosexist and homophobic attitudes persist (Rothmann and Simmonds 2015; De Wet, Rothmann and Simmonds 2016). These findings are indicative of student-teachers' conflict between what human rights are and could be, and between what human rights are on paper and what they are in reality (Du Preez and Becker 2016). Clearly, teacher education must contribute towards teachers' human rights literacy so that they, too, can move towards equity and inclusion. Teachers are not the only professionals positioned to promote sexual equality, and neither does one need to be a professional to be a change agent. Therefore, higher education could inspire students who will enter other professions and occupations to inspire transformation wherever they encounter human rights issues in general, and sexuality issues in particular.

Undeniably, as illustrated above, a need for transformative (teacher) education on sexual and gender diversity in general and, in particular, on understandings of (sexual) equality exists. Against the background of sexual minorities' unequal treatment and experiences combined with teachers' unpreparedness to challenge inequality and oppression, this article aims to re-imagine the language of equality towards transformative education. Given the author's standing as an Education Law specialist, the focus will, in particular, be on how legal conceptualisations of equality interact with conceptualisations of equality and equity within the education system, as well as how these interactions could inform transformative teacher education specifically, but also higher education in general. The section to follow problematises language related to sexual diversity and sexual equality, and makes an argument that the language of equality ought to be re-imagined before education can be transformed towards greater equity. Following the conceptual-theoretical framework, the article draws from empirical data collected in phase two (2015) of the project titled 'Human Rights Literacy: A search for meaning' (Roux and Du Preez 2013) to explore how students in higher education institutions conceptualise sexuality and sexuality rights within a human rights discourse. The paper then concludes with notes on reimagining the language of equality through understanding how inequalities are perpetuated within current conceptualisations of equality. 


\section{A ROSE BY ANY OTHER NAME? PROBLEMATISING THE LANGUAGE OF SEXUAL EQUALITY}

Both in law and curriculum, the notion of sexual equality depends on the use of language to describe both the status quo and the 'place' of equality and inclusion we strive towards. A rose by any other name may smell as sweet, yet, how we conceptualise the words we use when we talk about sexual difference and sexual equality plays an important role in either challenging or perpetuating oppression and discrimination based on these differences. De Vos (2008, 256) rightly argues that 'the construction of sexual subjects on the basis of an assumed heteronormative model' ought to be resisted. Heteronormativity in this sense is understood as institutions, structures of understanding and practical orientations that make heterosexuality the norm/normal and privileged (Ryle 2012; Francis and Msibi 2011; Berlant and Warner 1998). The heteronormative model assigned 'deviant status' to diverse genders and sexualities, particularly those experiencing same-sex attraction, and 'channelled sexual possibilities into one particular sexual orientation or identity' (Collier 2002, 91). Such a culture affords privilege and benefits to (perceived) heterosexuals, while it disciplines and oppresses those who are perceived as unusual (Francis and Msibi 2011; De Vos 2008). As aptly put by De Vos (2008, 4):

In a heteronormative world, discursive practices as well as legal regulation help to construct a hierarchy of sexual desires, practices and identities and this hierarchy has a disciplining force that influences the way we understand and order the world through law, yes, but also through other social practices.

De Vos $(2008,257)$ holds that the binary found in identity groups such as 'heterosexual' or 'homosexual' contributes to the 'disciplining power' of a heteronormative culture and could perpetuate the heteronormative assumptions that resulted in creating these groups in the first place. Along these lines, 'sexual orientation' often denotes an assumption that a person is born with a specific sexuality, while others may use 'sexual preference' or 'lifestyle choice', viewing sexuality as a (deviant) choice a person makes (Ryle 2012). However, whether sexuality is inborn or chosen is irrelevant when one considers the effect heteronormativity has on sexual minorities.

The Constitutional court in National Coalition for Gay and Lesbian Equality v Minister of Justice (1999) defined 'sexual orientation' to include all who are erotically attracted to members of their own sex, even on a single occasion. In an attempt to be as inclusive and respectful as possible, popular and academic literature have added to a growing list of concepts 
(gay, lesbian, bi-sexual, transgender, queer, questioning, a-sexual, inter-sexed, pan-sexual, omni-sexual) through the process of 'constantly honing and adjusting language' (Killermann 2016, 1). Nonetheless, many of these 'categories' and, perhaps, the very fact that society somehow needs them, could be indicative of a heteronormative perspective on sexuality: Society still distinguishes between heterosexual and the 'other'. Moving away from the heterosexual/homosexual dichotomy would acknowledge the existence of a range of sexual experiences and (non)interests. Simultaneously, given that those who identify themselves as LGBTQ+ are now exercising their agency, we are reclaiming concepts from the heteronormative model and may end up viewing a particular self-defined identity as offering 'a sense of personal harmony, social location and even at times a political commitment' (Wekesa 2016, 33).

In an attempt to acknowledge the fluid nature of sexuality and sexual identities, the use of 'sexual difference and diversity' as opposed to 'sexual orientation' is preferred. Sexual difference and diversity is understood as referring to a wide range of emotional and sexual attractions, desires, practices and identities experienced by individuals (difference) and groups (diversity). Such understanding aims to move away from the binary of the traditional 'heterosexual' and 'homosexual' categories of difference towards recognising and celebrating the richness of differing emotional and sexual attractions, experiences and identities we enjoy. That said, the experiences of oppression, marginalisation, exclusion and inequality shared by groups or individuals belonging to or identifying themselves as LGBTQ+ are not to be ignored (De Vos 2008). Therefore, 'sexual minorities' may be used to describe groups and individuals whose social and sexual practices might mark them as 'other' within a heteronormative environment. This concept does not suggest that individuals who are not exclusively heterosexual are necessarily in the minority in as far as numbers are concerned (here the Kinseyscale can be cited as an example) (The Trustees of Indiana University Kinsey Institute 2016), nor does it deny agency on the part of sexual minorities. ${ }^{1}$ The use of 'sexual minorities' should, therefore, take cognisance of both agency and oppression within a non-binary understanding of sexuality.

According to Tomás (2015, vii), sexual oppression can be viewed as 'a matter of domination and exclusion of the Other, intersecting the axes of social difference and inequality'. Within this framework of oppression, relationships between heterosexuals and sexual minorities are understood as having been constructed by heteronormativity, resulting in powerdifferences at the expense of sexual minorities (Francis and Msibi 2011). In this sense, the rights of sexual minorities need to be upheld and promoted within an existing system of social 
inequality and oppression brought about by heteronormativity. We should choose the language we use carefully so as to avoid perpetuating oppression.

Against the background of heteronormativity, inequality and oppression on the grounds of sexual difference and diversity, the Constitution of the Republic of South Africa, 1996 (Act No. 108 of 1996) (hereafter the Constitution) attempts to 'heal the divisions of the past and establish a society based on democratic values, social justice and fundamental human rights' by, inter alia, affording equal rights to sexual minorities. De Vos $(2008,259)$ however argues that despite these ideals, equality discourses still tend to focus on similarities rather than on differences. For this reason, the paragraphs to follow will explore conceptualisations of both equality and equity against the backdrop of a need for transformation.

In support of Section 9 of the Constitution, the Promotion of Equality and Prevention of Unfair Discrimination Act, 2000 (Republic of South Africa 2000) (hereafter the Equality Act) as a form of 'transformative' or 'anti-discrimination' legislation promotes (sexual) equality in both vertical and horizontal relationships (Kok 2014, 3). Intended to promote equality and to prevent, prohibit and eliminate unfair discrimination, harassment and hate speech, this act's preamble envisages transformation towards a society 'united in its diversity, marked by human relations that are caring and compassionate, and guided by the principles of equality, fairness, equity, social progress, justice, human dignity and freedom' (Equality Act, preamble). Despite contending that human rights uphold appropriate political norms mainly in as far as how people ought to be treated by their governments, Tomás (2015) agrees that both the Constitution (section 8(2)) and the Equality Act imply that equality rights are applicable to private behaviour. As such, the law commits the State as well as ordinary and legal persons to the goal of achieving (sexual) equality. In addition, it sends a 'strong moral message that it views discrimination as ... evil', whilst 'at its most ambitious and idealistic ... [aims to] reach into the hearts, minds and homes of its subjects, and affect fundamental changes in basic social relationships' (Kok 2014, 2-3).

Generally, equality is understood either as a formal conceptualisation referring to sameness of treatment or a substantive conceptualisation which refers to sameness in terms of the outcomes of the law (Currie and De Waal 2015). Due to the inability of formal equality to bring about equal results or outcomes, the overall consensus is to interpret equality as meaning substantive equality. ${ }^{2}$ Currie and De Waal $(2015,24)$ note that the transformative commitment of the Constitution 'requires understanding the constitutional value of equality as a process towards the goal of an equal society'. Similarly, Yacoob (2016) pointed out that the Constitution contemplated a kind of society in which the vulnerable are protected and enjoy equal rights. 
Against the background of the values of human dignity, the achievement of equality and the advancement of human rights and freedoms as espoused in section 1(a) of the Constitution, section 9(2) goes on to state that equality includes the full and equal enjoyment of all fundamental rights and freedoms. This is echoed in the definition of equality contained in the Equality Act which adds explicitly that equality 'includes de jure and de facto equality and also equality in terms of outcomes'. Equality, therefore, boils down to a person not merely being an equal bearer of rights and duties but also as having the right to be treated equally. The Constitutional Court as well as the Equality Act made it clear that equality is not to be in the letter alone but ought to be part of the everyday lived experiences of those who reside in South Africa. Such substantive conceptualisation of equality corresponds with the notion of equity, understood to have a direct bearing on fairness and social justice (Simmonds 2013).

As part of their right to equality, people have the right not to be unfairly discriminated against (see sections 9(3) and 9(4) of the Constitution as well as section 6 of the Equality Act). Unfair discrimination is defined as 'any act or omission, including a policy, law, rule, practice, condition or situation which directly or indirectly ... imposes burdens, obligations or disadvantage on; or withholds benefits, opportunities or advantages from, any person on one or more of the prohibited grounds' (Equality Act, section 1). 'Sex', 'gender' and 'sexual orientation' are explicitly listed as prohibited grounds (Constitution, section 9(3)), an inclusion which De Vos (1996), Francis and Msibi (2011) and Cameron (2015) view as particularly progressive. The Constitution furthermore provides that discrimination on one or more of these (listed) grounds would automatically be viewed as unfair until the contrary can be established (section 9(5)).

Central to the conceptualisation of unfair discrimination are the values of dignity and freedom: In line with the Constitutional Court's argument (Harksen v Lane LO, 1998) regarding grounds equivalent to those listed in section 9 (SA 1996), the Equality Act extended the definition of 'prohibited grounds' to include 'any other ground where discrimination based on that other ground ... causes or perpetuates systemic disadvantage; undermines human dignity; or adversely affects the equal enjoyment of a person's rights and freedoms in a serious manner' (section 1). Thus, sexual oppression as described earlier should be understood as unfair discrimination - conduct that can and should be challenged by using the rights, duties, procedures and remedies put forward by the Equality Act.

Despite legal protection of sexual equality, law and its implementation have not always translated into changed lived experiences for sexual minorities (De Vos 2015b; Francis and Msibi 2015; Rothmann and Simmonds 2015; De Wet, Rothmann and Simmonds 2016). A 
paradox is revealed indicating that although sexual minorities possess human rights and have access to justice, they do not necessarily enjoy equal rights and justice. The paradox between the existence and non-existence, possession and non-possession, realisation and non-realisation of human rights has been highlighted by various scholars (Rancière 2004; Dembour 2010; Donnelly 2013; Moyn 2014; Becker and Du Preez 2016). As Becker and Du Preez (2016, 63) pointed out, written statements of human rights are inherently paradoxical in that they imply the '[non] existence of human rights'. Donnelly $(2013,9)$ reasons that having a right is of greatest value when one does not have it, but that one can 'have' and 'not have' (enjoy) a right at the same time. In addition, human rights in some contexts may be viewed as a 'double-edged sword' which simultaneously protects and causes harm to the subjects of the rights (De Wet, Rothmann and Simmonds 2016; De Vos 2009).

Discourses concerning equity, as opposed to equality, generally allude to the gap between minority groups' experiences of inequality on the one hand and, on the other, equality as legal right, legally protected and enforceable. In this regard, De Vos $(2009,6)$ views the law and human rights as lacking the capacity to affect social change and address oppression. Kok (2010, 61) shares in this 'pessimism about the potential role of law in transforming society'. Francis (2011) adds that because religious, cultural, behavioural and personal components complicate sexuality, laws are inadequate to protect sexual rights. This is one reason why equality is 'a difficult and deeply controversial social ideal' (Currie and De Waal 2015). Moreover, the practices that implement law and policies take place in a world that is real rather than ideal (Harley et al. 2000), a world where intricate complexities often disrupt sexual equality. The law itself is framed within a heteronormative system, as the conceptualisation of 'sexual orientation' would illustrate (De Vos 2008, 260).

Equality conferred by (even transformative) law does not always 'unsettle the institutions, structures of understanding, and practical orientations' that normalise heterosexuality but 'merely accommodate new forms of recognition on the template of the existing heterosexual norm' (De Vos 2008, 11). The Equality Act illustrates this point: Sexual diversity or sexual orientation has not been mentioned explicitly in the act save from it being listed as a 'prohibited ground'. Although the preamble makes reference to gender discrimination and oppression in a patriarchal system, it is silent on sexual discrimination and oppression in a heteronormative system. The act fails to define sexuality or sexual orientation, although it defines 'sex' as including intersex and 'marital status' as including same-sex unions (gender is not defined). Chapter 2 of the act explicitly prohibits discrimination on grounds of race (section 7), gender (referring to discrimination against women and girls) (section 8) and disability (section 9) but 
affords no special mention to sexuality or sexual orientation, thus failing to challenge the heteronormative system within which the act is supposed to protect sexual minorities. As long as heteronormativity itself is not challenged, the law - even when embracing substantive notions of equality - fails to 'transcend the heteronormative assumptions of the state, of the law and of our culture and seldom recognises the freedom that is associated with the right to be different' (De Vos 2008, 260). This beckons a reimagining of the equality discourse.

Data from an empirical study was used to probe how students in higher education institutions conceptualise sexuality and sexuality rights within a human rights discourse.

\section{EMPIRICAL RESEARCH STRATEGIES}

Research in the project followed a rhizomatic design and data was collected in two phases (Roux and Du Preez 2013; Roux and Becker 2015). Phase 1 collected data during 2012 and 2013 from seven South African University sites by using three different data collection strategies: a walk-about2012, a survey2013 and focus-group discussions (FGD 2013$)$. Phase two collected data in 2015 from eight university sites in six different countries by using three collection strategies: a survey2015, focus-group discussions 2015 (FGD 2015$)$ and e-mail responses2015. Data from the first phase has already been disseminated by means of articles and conference papers. ${ }^{3}$ In this article, I will draw on data collected with survey2015. The sample, procedure, collection instrument and analysis are briefly explained below.

\section{Participants and procedure}

Students were purposely selected from faculties or schools of education, sociology, law and political sciences. These students were selected on the basis that they either did a module in human rights or/and may be confronted with human rights issues in their professional environments. Eight institutions were selected for participation. After obtaining permission and ethical clearance at the hosting university as well as research sites, students on each site were approached via gatekeepers (lecturers). Upon invitation, students were provided with a link to the online questionnaire. Invitation took place face to face in some instances and in other instances via electronic learning platforms. Across the eight sites, 434 students accessed the questionnaire and indicated that they were willing to participate. After agreeing to ethical terms and conditions (informed consent, privacy and confidentiality statement - $\mathrm{S}_{2015} \mathrm{Q} 1$ ), 83 left the survey despite their initial willingness to participate. The survey was completed by 351 participants ( $\mathrm{n}=351)$. Access to and participation in the survey is depicted in Table 1. 
Table 1: Sample breakdown per country

\begin{tabular}{|l|r|l|}
\hline \multicolumn{1}{|c|}{ Sample-segment } & n= & \multicolumn{1}{c|}{ FacultylSchool } \\
\hline Germany sample & 25 & Education students \\
\hline India sample & 84 & $\begin{array}{l}\text { Education, law, political and } \\
\text { sociology students }\end{array}$ \\
\hline South Africa sample & 136 & Education and sociology students \\
\hline Norway sample & 1 & Theology students \\
\hline Israel sample & 60 & Education students \\
\hline Netherlands sample & 45 & Education students \\
\hline Total participants & $\mathbf{3 5 1}$ & \\
\hline Accessed survey but did not participate & 83 & \\
\hline Total accessed survey & $\mathbf{4 3 4}$ & \\
\hline
\end{tabular}

At the time of their participation in the survey, participants were in their first ( $n=7 / 351$ ), second $(n=50 / 351)$, third ( $n=33 / 351)$ or fourth $(n=150 / 351)$ year of study $\left(S_{2015} Q 4\right)$. Some participants were post-graduate students. Participants represented a variety of belief systems ( $\left.\mathrm{S}_{2015} \mathrm{Q} 7\right)$, ethnicities $\left(\mathrm{S}_{2015} \mathrm{Q} 12\right)$ language groups $\left(\mathrm{S}_{2015} \mathrm{Q} 13\right)$ and countries of birth $\left(\mathrm{S}_{2015} \mathrm{Q} 9\right)$. Of particular interest for this article are the sex and sexuality of participants.

While the author recognises gender as fluid within a queer understanding of gender (Ryle 2012), the questionnaire did ask participants to indicate their 'biological sex' ( $\left.S_{2015} Q 5\right)$ and to do so in terms of a male/female binary. Nevertheless, the question had a 100 per cent response rate. The sex of participants is depicted in the chart below, which shows that 'female' participants were just more than double the number of 'male' participants:

\section{$\mathrm{S}_{2015} \mathrm{Q} 5$ : What is your biological sex? $(\mathrm{n}=351 / 351)$}

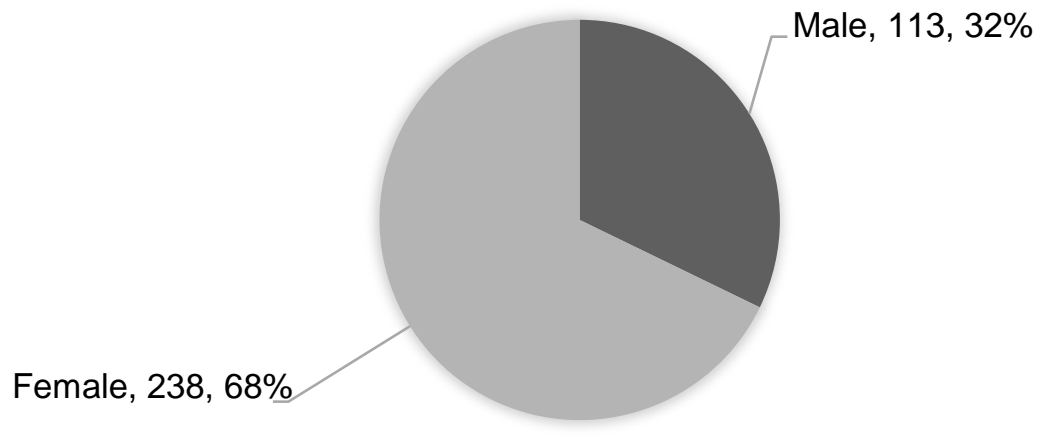

Figure 1: Biological sex of participants $\left(\mathrm{S}_{2015} \mathrm{Q} 5\right)$

Pertaining to the sexualities of participants, the chart below depicts the 'sexual orientation' of participants. Although the term 'sexual orientation' is viewed as problematic (see paragraph 3.1), it was used in the questionnaire based on an assumption that students would be most familiar with the term and its associated categories as often used in law and in LGBTQ+ 
literature. The chart will illustrate that at least 17 per cent of respondents identified with sexual minorities.

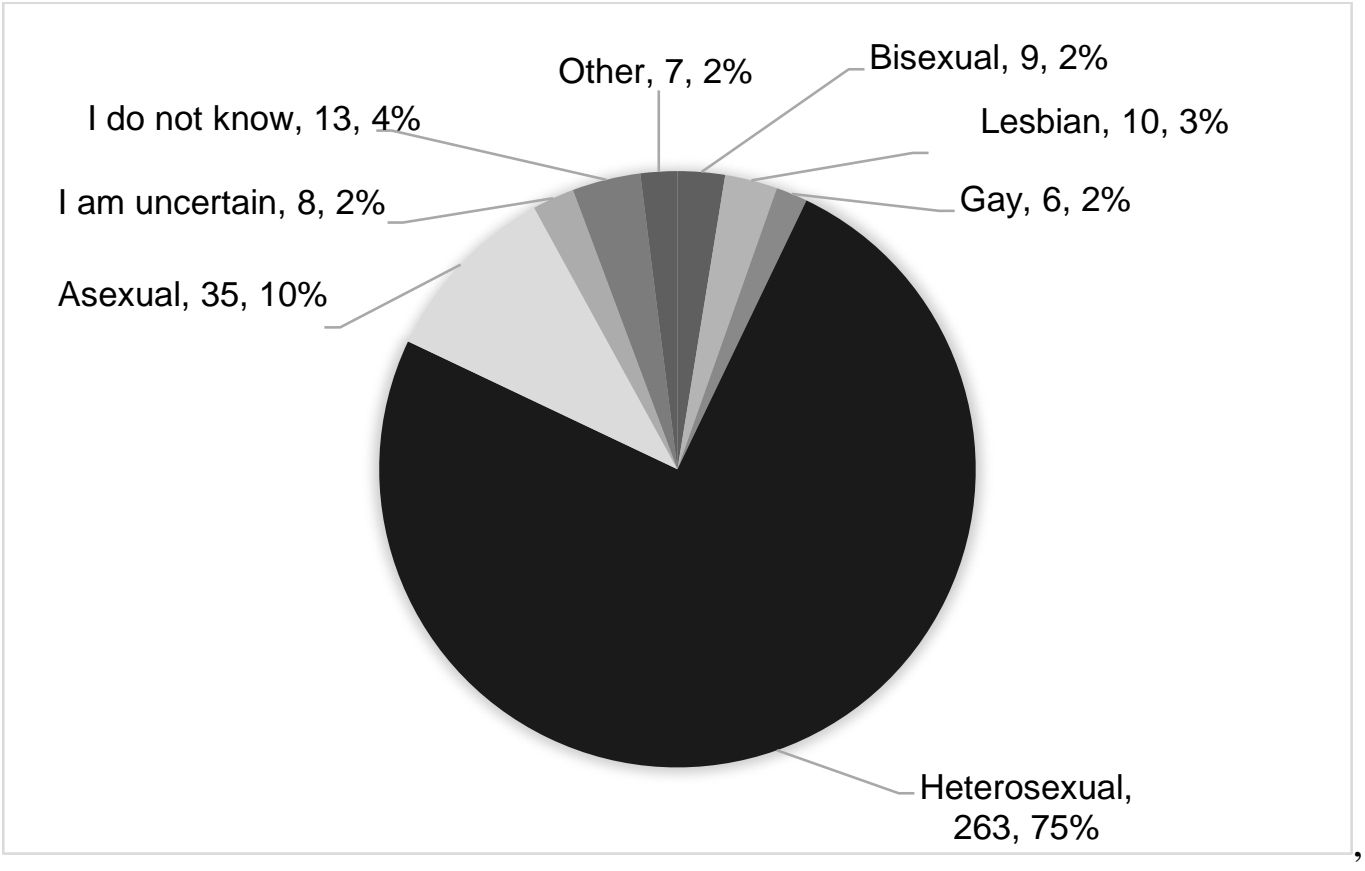

Figure 2: Sexual orientation of participants $\left(\mathrm{S}_{2015} \mathrm{Q} 6\right)$

\section{Data collection instrument}

The questionnaire used for survey2015 consisted of 56 questions, probing students' conceptualisations and understandings of human rights and human rights education. Question 1 dealt with ethical issues such as informed consent, privacy and confidentiality. Three questions determined how students understand human rights in terms of sexuality. Each question provided a statement and requested participants to respond by indicating on a fivepoint scale to what degree they agreed or disagreed with the statement $(1=$ totally disagree, 5 $=$ totally agree). The questions relevant to this article are:

- $\quad$ Question 27: Everyone has the right to pursue a sexual orientation of their choice

- $\quad$ Question 28: People do not have the right to discriminate against others because of their sexual orientation

- Question 29: Children in schools should have the freedom to express their sexual orientation

To further illuminate some of the findings from the three questions above, responses for two non-Likert type questions are brought in conversation with the responses to Questions 27 to 29 . These are Question 17 which asked students to select from a list the three words or phrases they 
associate most with human rights, ${ }^{4}$ and Question 25 which probed students' conceptualisation of freedom by asking them so select from a list of words or phrases the five they associate with freedom the most. ${ }^{5}$

\section{Data analysis}

Quantitative data from the survey was analysed by using descriptive statistics. Tables with means and standard deviations are used to illustrate these findings, referencing the question number, for example $S_{2015}$ Q26 where $S_{2015}$ refers to the second-phase survey and Q26 denotes the question number. Participants were free to skip any questions, and thus not all questions were answered by all 351 participants. For each question, the number of participants who answered the question are indicated as, for example, $n=241 / 351$, where the first number indicates the number of responses and the second number the total number of participants for the survey.

The theoretical and philosophical lenses used when analysing the data reflect the underlying principles associated with the critical theoretical paradigm, insofar as it could aid the uncovering of underlying gendered and sexualised structures which may either challenge or reinforce inequality and oppression (Ponterotto 2010; Ponterotto 2005). This allowed critique and questioning of the status quo and human rights tools in the sense that they fail to bring about transformation. Within this theoretical/philosophical framework, participants' conceptualisations of what sexual equality could mean are explored critically.

\section{STUDENTS' CONCEPTUALISATIONS OF HUMAN RIGHTS AND SEXUALITY}

Survey data revealed the gap between understandings of equality and non-discrimination as formal equality on the one hand and equity, or substantive equality, on the other. Table 2 depicts the responses to the four questions on gender and sexuality:

Table 2: Human rights, gender and sexuality

\begin{tabular}{|c|c|c|c|c|}
\hline $\begin{array}{l}\text { Question } \\
\text { number }\end{array}$ & Question & $\mathbf{n}$ & Mean* & $\begin{array}{l}\text { Standard } \\
\text { Deviation }\end{array}$ \\
\hline $\mathrm{S}_{2015} \mathrm{Q} 27$ & $\begin{array}{l}\text { Everyone has the right to pursue a sexual orientation } \\
\text { of their choice }\end{array}$ & $310 / 351$ & 1.46 & 0.95 \\
\hline $\mathrm{S}_{2015} \mathrm{Q} 28$ & $\begin{array}{l}\text { People do not have the right to discriminate against } \\
\text { others because of their sexual orientation }\end{array}$ & $310 / 351$ & 1.31 & 0.81 \\
\hline $\mathrm{S}_{2015} \mathrm{Q} 29$ & $\begin{array}{l}\text { Children in schools should have the freedom to } \\
\text { express their sexual orientation }\end{array}$ & $310 / 351$ & 1.85 & 1.18 \\
\hline
\end{tabular}

* The mean represents the level to which students agreed with each statement, where the minimum value of

1 represents 'I fully agree' and the maximum value of 5 represents 'I totally disagree'.

On examining the responses closely, an interesting trend can be identified as the questions move from the right to choose freely (Question 27) and the (non)right to discriminate (Question 28) 
to the right to freely express sexuality (Question 29). Responses to Question 27 (see Table 2) indicate that participants mostly agree that every person should enjoy the freedom of choice regarding their sexual orientation. In the light of differing conceptualisations of sexual orientation and sexual diversity as described in paragraph 3.1, it is impossible to say whether students understood this freedom as related only to erotic attractions and activity, or whether emotional attraction and experience were included. Nevertheless, participants seem to place a high value on choice as a liberty they associate with human rights and as such, they would not interfere with another person's choices when it comes to sexuality.

Question 27 combines sexual orientation, presumed as something one was born with (Ryle 2012), with both sexual preference, presumed as a choice (Ryle 2012) and an action, namely to pursue one’s sexual orientation or identity. Participants' responses can, therefore, be interpreted as revealing a positive attitude towards all three of these aspects of sexuality. When selecting from a list of 11 words or phrases those they associated most with freedom (Question 25), 138 of participants selected 'choice of sexual orientation', ranking it fifth out of eleven phrases. It thus becomes clear that students conceptualise freedom and choice as part of sexual equality. Participants' understanding of freedom as freedom of choice in relation to human rights probably motivated their endorsement of sexual orientation and/or preference or lifestyle choices at Question 27.

Question 28 went one step further to ask whether participants are of the opinion that people have a right to discriminate against others on the basis of their sexual orientation. Here, the mean of 1.31 (see Table 2 above) is even more positive than the responses to Question 27, indicating that the vast majority of participants feel strongly that one should not discriminate against someone because of his or her sexuality. Responses to Questions 27 and 28 create the impression that participants have accepted or embraced sexual diversity and recognise sexual equality. Such positive responses give hope that students have started to move away from compulsive heterosexuality and heteronormativity (Ryle 2012) towards inclusion, or at least tolerance.

The positive responses for Question 28 are in contrast with findings of authors such as Msibi (2012, 12), Francis (2016), Rothmann and Simmonds (2015) and Francis and Msibi (2011). A possible explanation could be that students conceptualise equality and nondiscrimination as a legal rule that should be heeded. When the responses to Question 27 and 28 are read with the responses to Question 17 (words or phrases associated most with human rights), it seems that participants have a high awareness of legal aspects of rights. 'Declaration of Children’s Rights' ranked second ( $n=228)$, 'Legal protection’ third $(n=209)$ and 'Bill of 
rights' fourth ( $\mathrm{n}=186)$ out of eleven phrases. Responses may indicate an awareness of legal protection towards (sexual) equality, as reflected by the second, third and fourth ranking phrases. Participants possibly understand (sexual) equality as related to a level of formal equality between people (e.g. sexual minorities and heterosexuals), knowing all are equal bearers of rights (Currie and De Waal 2015). However, participants may be unaware of or only slightly affected by the more subtle and opaque discrimination which results from heteronormativity and heterosexism.

Participants hold a strong view that sexual equality includes freedom of choice and that one shouldn't discriminate, but it does not necessarily mean that they wouldn't. To further probe participants' attitudes in this regard, the next question focused on the expression of sexuality within the school context.

Responses to Question 29 (see Table 2) are represented by a mean of 1.85 which stands in contrast to responses for the previous two questions: The higher mean indicates that fewer participants fully agreed with the statement, although most participants still agreed to some extent. It seems that while participants feel very strongly about a person's rights in terms of choice (Question 27) and non-discrimination (Question 28) irrespective of his or her sexuality, they are less comfortable with the idea of children expressing their sexuality in the school setting.

Since Question 29 did not distinguish between heterosexuals and sexual minorities, the responses could apply to all children. ${ }^{6}$ By implication this would mean that heterosexuals and sexual minorities are treated equal in the sense that children should not express their sexuality, irrespective of their sexual identity/orientation. This corresponds with indications by Allen (2007) and Francis (2011) namely that adults prefer viewing children as child-like and innocent rather than active sexual subjects. At the same time, disagreeing from the statement posed by Question 29, or only partially agreeing, indicates that participants do not associate sexual expression (of children) with human rights. One interpretation is that participants are of the opinion that neither heterosexual nor sexual minority children in schools should 'have the freedom to express their sexual orientation'. It is, however, unlikely that sexual expression is not conceptualised as part of sexual equality in the light of responses to Question 25 (phrases associated with freedom): 'Freedom to express oneself' ranked second out of $11(n=210)$. This leaves us with the question why participants would limit free sexual expression in Question 29. The notion of heteronormativity may prove helpful in this regard: Within the heteronormative framework that is prevalent in society, one could argue that the words 'sexual orientation' in the questions asked are interpreted by participants as meaning 'non-heterosexual sexual 
orientation'. The law itself is framed within a heteronormative background and the courts defined sexual orientation as referring to non-heterosexual orientation (see paragraph 2). Therefore, participants in the survey possibly answered Question 29 with non-heterosexual expression in mind. According to this interpretation, responses to Question 29 probably indicate that participants are only comfortable with the sexual other as long as their otherness are not expressed in the school setting. This interpretation is supported by literature which indicates a general view that sexual expression by heterosexuals is normal, but that non-normative sexual orientations should be kept private (De Vos 2005a).

In the light of ample evidence of sexual inequality, responses could indicate students' conceptualisations of (sexual) equality as leaning more towards formal than substantive equality. A focus on formal equality without an understanding of substantive equality (equity) would mask the sexual inequalities in society. The findings may indicate students' acceptance and internalisation of sexual equality only as formal legal rules. However, they may lack an awareness of the gap between formal equality and substantive equality and the inequalities that play out in this gap. Limiting the sexual expression of sexual minorities but not of heterosexuals is one example of such inequalities.

Findings reported here indicate that the non-translation of legal rights into inclusion and equality for sexual minorities might be due to the gap between formal and substantive conceptualisations of equality. The acknowledgment of equal rights for sexual minorities therefore appears to be superficial, revealing a lack of awareness regarding personal responsibility for the inclusion of the other within horizontal relationships. It seems that many students are willing to extend 'protection to gay men and lesbians as long as they behave in a way that would not threaten the heteronormative assumptions underlying citizenship' (De Vos 2008, 255). These assumptions could include children as innocent and non-sexual, as well as heterosexual expressions as the norm.

By considering equality to mean that people are equal bearers of rights, the different sexualities may indeed appear to be equal while oppression based on sexuality could still be present. Students' understanding of equality as formal equality may leave a gap in their ability to identify incidences of sexual inequality they may have witnessed or experienced. Moreover, it would prevent reflection on their own attitudes and conduct which could serve as basis for transformative action. Considering the role of teachers in human rights education as well as the protection and promotion of human rights within education spaces, the language of (sexual) equality in teacher-education should deliberate the gap between formal and informal conceptualisations of equality. Sexual equality should be discussed against the background of 
heteronormativity and sexual expression to explore the subtle ways in which sexual inequalities play out despite formal and legally enforceable equality.

\section{REIMAGINING THE LANGUAGE OF SEXUAL EQUALITY}

Moving towards the realisation of human rights and sexual equality (or rather equity) requires conceptualisations of equality within human rights literacies that would promote transformative action by lecturers, state and school/university officials, teachers, students and learners. It has been argued that human rights literacies (HRLit) require an internalisation and implementation of human rights and human rights values through the processes of rights-based education and transformative action (Becker, De Wet, and Van Vollenhoven 2015). Roux and Becker (2015) as well as Simmonds (2014) propose that human rights literacy should include 'skills, knowledge and actions with internalised human rights values' which could open spaces where role-players can engage with complex human rights issues such as sexuality. In this regard, the role of teacher education and the language used when talking about sexuality in teacher education needs to be considered.

The realisation of human rights in schools through the application as well as teachinglearning thereof is aimed, among others, at developing a sense of social justice and contributing towards the eradication of various forms of discrimination and oppression, such as heterosexism and homophobia. Transformation in and through education corresponds with article 26(2) of the Universal Declaration of Human Rights (United Nations 1948) which commits education towards 'strengthening of respect for human rights and fundamental freedoms' and promoting 'understanding, tolerance and friendship'.

Teachers are central to the effort of promoting human rights in and through education and should be well equipped to contribute to this endeavour. Yet, as this research has pointed out, teachers, learners and students seem to overlook sexuality issues and lack conceptualisations of equality that motivate their transformative action. Rather, the current language related to sexual equality (including in law, curriculum and as used by students) may perpetuate inequality and heteronormativity. Roux and Becker (2015) as well as Keet (2012) point towards the absence of an intrinsic knowledge construct and lack of rigorous discourses on the philosophical, ontological and epistemological underpinnings of human rights education in teacher education. This gap between enforceable legal human rights (such as equality) and the non-realisation of rights in the education system is amplified by the different manners in which power, domination and inequity shape human rights law, understandings, experiences and actions within cultural, religious, historical and social contexts (Johnson, Pete and Du Plessis 2001; Dale and Hyslop- 
Margison 2010; De Vos 2015b). Reimagining equality discourses in teacher education is and should be aimed at this gap. As such, (sexual) equality should not only be known and understood as cognitive skills and legal rights, but also as social practices, alluding to how people act, inter-act and react on abstract human rights documents within their specific sociocultural contexts (Roux and Becker 2015). This re-imagined language of sexual equality should be heard in policy, curriculum, discourses and all other aspects of teacher education and the higher education institutions responsible for teacher education. Teachers who are adequately prepared for their transformative role might become change agents in their schools, employing language in imaginative ways to challenge oppression and promote sexual equality. Such reimagining of equality-related language should however not be limited to teacher education only. Higher education institutions could inspire transformation by reimaging and incorporating sexual equality language and discourses on institutional level as well as through teachinglearning in other (non-education) programmes.

\section{CONCLUSION}

Human rights and the transformative legislation that aims to protect and promote them already take us forward in our struggle against oppression and the eradication of unfair discrimination. However, the ways in which we conceptualise equality, and particularly when conceptualisations lean towards the formal and the legal only, are not enough to motivate transformative action and inclusion on the side of the role-players in education. Current conceptualisations of equality does not necessarily recognise sexual oppression nor does it always involve inclusion. Reimagining conceptualisations of equality requires human rights literacy as discursive spaces between not only knowledge and skills in understanding the right to equality but also internalised values and beliefs that would change attitudes and spur transformative action and inclusion. Within teacher education in particular, and higher education in general, human rights literacy could re-conceptualise equality as both cognitive skills (knowledge of human rights documents, remedies and values) and social practices (the processes and consequences of human rights) that could lead to social change and sexual equality.

\section{ACKNOWLEDGEMENT}

This work is based on a research project supported by the National Research Foundation (NRF) of South Africa (Grant Number 81785) 2012-2015. The grant holder Prof Cornelia Roux acknowledges that opinions, findings and conclusions or recommendations expressed in any 
publication generated by the NRF-supported research are those of the author(s), as members or collaborators of the project, and that the NRF accepts no liability whatsoever in this regard.

\section{NOTES}

1. Francis (2016) highlighted the problematics of framing sexual diversities within a 'victim-agency dualism'.

2. See for example National Coalition for Gay and Lesbian Equality v Minister of Justice, 1999; Harksen v Lane NO, 1998, and President of the Republic of South Africa v Hugo, 1997.

3. Articles related to sexuality are De Wet, A., J. Rothmann and S. Simmonds. 2016. Human rights: Protecting sexual minorities or reinforcing the boundaries of 'the closet'? South African Review of Sociology 47(3): 85-109; and Rothmann, J. and S. Simmonds. 2015. 'Othering' non-normative sexualities through objectification of 'the homosexual': Discursive discrimination by pre-service teachers. Agenda 2015: 1-11. For a full list of publications and papers, see www.HRLit.org.

4. The list contained the following words/phrases: Women's rights; Declaration of Children's Rights; Legal protection; Bill of rights; Government's responsibility; Gender legislation; Constitutions of nations; United Nations; Code of conduct; Police protection.

5. The list contained the following words/phrases: Choice of opinion, belief and religion; Express oneself; Being without fear; No oppression; Choice of sexual orientation; Non-violent society; Responsibility; Choice of movement; Freedom of association; Free to participate in cultural practices and rituals; To be allowed to participate in mass action.

6. This is, if respondents understood sexual orientation as meaning patterns of emotional, romantic, and sexual attraction and personal and/or social identities based on those attractions. Such understanding would include heterosexual attraction, in contrast to the definition of sexual orientation by South African Constitutional Court as attraction to persons of the same sex.

\section{REFERENCES}

Allen, L. 2007. Denying the sexual subject: Schools' regulation of student sexuality. British Educational Research Journal 33(2): 221-234.

Barnard-Naudé, J. and O. de Vos. 2011. The heteronormative observer: The constitutional court's decision in Le Roux v Dey. South African Law Journal 11(3): 407-419.

Becker, A., A. de Wet and W. J. van Vollenhoven. 2015. Human rights literacy: Moving towards rightsbased education and transformative action through understandings of dignity, equality and freedom. South African Journal of Education 35(2): 1-12.

Becker, A. and P. du Preez. 2016. Ideological illusion, human rights and the right to education: The in(ex)clusion of the poor in post-apartheid education. Journal of Education 64: 55-78.

Berlant, L. and M. Warner. 1998. Sex in public. Critical Inquiry 24(2): 547-566.

Cameron, E. 2015. Justice: A personal account. Cape Town: Tafelberg.

Collier, R. 2002. Masculinity, law and the family. London: Routledge.

Currie, I. and J. de Waal. 2015. The Bill of Rights handbook. 6th Edition. Cape Town: Juta and Co.

Dale, J. and E. J. Hyslop-Margison. 2010. Paulo Freire: Teaching for freedom and transformation. London: Springer.

De Vos, P. 1996. Same-sex marriage, the right to equality and the South African constitution. SAPR/PL 11: 355-382.

De Vos, P. 2008. From heteronormativity to full sexual citizenship? Equality and sexual freedom in 
Laurie Ackermann's constitutional jurisprudence. In Constitutional Law dignity, freedom and the post-apartheid legal order: The critical Jurisprudence of Laurie Ackermann, ed. A. J. BarnardNaudé, D. Cornell, and F. du Bois, 254-272. Cape Town: Juta and Co.

De Vos, P. 2009. Refusing human rights: A Foucauldian account. In Refusal. Transition and postapartheid law, ed. K. van Marle, 121-140. Stellenbosch: Sun Press.

De Vos, P. 2015a. Mind the gap: Imagining new ways of struggling towards the emancipation of sexual minorities in Africa. Agenda 103(29): 39-53.

De Vos, P. 2015b. The limits of the law: Human rights and the emancipation of sexual minorities on the African continent. In Contested intimacies: Sexuality, gender and the law in Africa, ed. D. Higginbothan and V. Collins-Buthelezi, 1-18. Siber Ink in association with IAPO and Centre for African Studies: Cape Town.

De Wet, A., J. Rothmann and S. Simmonds. 2016. Human rights: Protecting sexual minorities or reinforcing the boundaries of 'the closet'? South African Review of Sociology 47(3): 85-109.

Dembour, M. 2010. What are human rights? Four schools of thought. Human Rights Quarterly 32: 120.

Donnelly, J. 2013. Universal human rights in theory and practice. Ithaca: Cornell University Press.

Du Preez, P. and A. Becker. 2016. Ontologies and possibilities of human rights: Exploring dissensus to facilitate reconciliation in post-conflict contexts. Perspectives in Education 34(3): 1-14.

Francis, D. 2016. 'Troubling' the teaching-learning of gender and sexuality diversity in South African education. Paper at a seminar of the subject group sociology in the School of Social and Government Studies, 31 August 2016, Potchefstroom, South Africa.

Francis, D. A. 2011. Sexuality education in South Africa: Wedged within a triad of contradictory values. Journal of Psychology in Africa 21(2): 319-324.

Francis, D. A. 2012. Teachers' positioning on the teaching of sexual diversity in South African schools. Culture, Health and Sexuality: An International Journal for Research, Intervention and Care 2012: 1-15.

Francis, D. A. and T. Msibi. 2011. Teaching about heterosexism: Challenging homophobia in South Africa. Journal of LGBT Youth 8: 157-173.

Johnson, D., S. Pete and M. du Plessis. 2001. Jurisprudence, a South African perspective. Durban: LexisNexis.

Harley, K., F. Barasa, C. Bertram, E. Mattson and S. Pillay. 2000. The real and the ideal: Teacher roles and competencies in South African policy and practice. International Journal of Educational Development 20(4): 287-304.

Keet, A. 2012. Discourse, betrayal, critique: The renewal of human rights education. In Safe spaces: Human rights education in diverse contexts, ed. C. Roux, 7-28. Rotterdam: Sense Publishers.

Killermann, S. 2016. It’s pronounced metrosexual. http://itspronouncedmetrosexual.com/ (accessed 20 September 2016).

Kok, A. 2014. 'The Promotion of Equality and Prevention of Unfair Discrimination Act 4 of 2000: How to balance religious freedom and other human rights'. Paper at the annual conference of the Association of the Study of Religion in South Africa (ASRSA) in Potchefstroom, 2014.

Kok, A. 2010. Is law able to transform society? South African Law Journal 127: 59-83.

Moyn, S. 2014. A powerless companion: Human rights in the age of neo-liberalism. Law and Contemporary Problems 77: 147-169.

Msibi, T. 2011. The lies we have been told: On (homo)sexuality in Africa. Africa Today 58(1): 54-77.

Msibi, T. 2012. 'I'm used to it now': Experiences of homophobia among queer youth in South African township schools. Gender and Education 24(5): 515-533.

National Coalition for Gay and Lesbian Equality v Minister of Justice. 1999. (1) SA 6 (CC).

Ponterotto, J. G. 2005. Qualitative research in counselling psychology. Journal of Counselling 
Psychology 52(2): 126-136.

Ponterotto, J. G. 2010. Qualitative research in multicultural psychology: Philosophical underpinnings, popular approaches, and ethical considerations. Cultural Diversity and Ethnic Minority Psychology 16(4): 581-589.

Rancière, J. 2004. Who is the subject of human rights? The South Atlantic Quarterly 103: 297-310.

Republic of South Africa. 1996. The Constitution of the Republic of South Africa Act 108 of 1996. http://www.gov.za/documents/constitution/constitution-republic-south-Africa-1996-1 (accessed 26 September 2016).

Republic of South Africa. 2000. Promotion of Equality and Prevention of Unfair Discrimination Act 4 of 2000. http://www.gov.za/documents/promotion-equality-and-prevention-unfairdiscrimination-amendment-act (accessed 26 September 2016).

Reygan, F. and D. Francis. 2015. Emotions and pedagogies of discomfort: Teachers' responses to sexual and gender diversity in the Free State, South Africa. Education as Change 19(1): 101-119.

Rothmann, J. and S. Simmonds. 2015. 'Othering' non-normative sexualities through objectification of 'the homosexual': Discursive discrimination by pre-service teachers. Agenda 2015: 1-11.

Roux, C. and A. Becker. 2015. Human rights literacy: A quest for meaning. European Wergeland Statement Series October 2015. http://thewc.org/statement/human.rights.literacy.the.quest.for. meaning/ (accessed 15 August 2015).

Roux, C. and P. du Preez. 2013. Introduction of project - Human rights literacy: A quest for meaning. http://www.hrlit.org/introduction-of-project-human-rights-literacy-a-quest-for-meaning/ (accessed 10 December 2016).

Ryle, R. 2012. Questioning gender: A sociological exploration. Thousand Oaks, CA: SAGE Publications.

SA see Republic of South Africa.

Simmonds, S. 2013. Curriculum implications for gender equity in human rights education. Ph.D. thesis, North-West University, Potchefstroom, South Africa.

Simmonds, S. 2014. Mapping the curriculum-making landscape of religion education from a human rights perspective. Journal of the Study of Religion 27: 129-153.

The Trustees of Indiana University Kinsey Institute. 2016. The Kinsey scale. https://www.kinseyinstitute.org/research/publications/kinsey-scale.php (accessed 26 September 2016).

Tomás, J. 2015. Introduction. In Sexuality, oppression and human rights, ed. J. Tomás and N. Epple. Oxford: Inter-Disciplinary Press.

United Nations. 1948. Universal Declarations on Human Rights. General Assembly resolution 217A. http://www.ohchr.org/en/udhr/pages/introduction.aspx (accessed 20 August 2016).

Wekesa, S. M. 2016. A constitutional approach to the decriminalisation of homosexuality in Africa: A comparison of Kenya, South Africa and Uganda. Pretoria: University of Pretoria. L.L.D. Thesis.

Yacoob, Z. 2016. Education, the Constitution and context. Keynote Report delivered during the Schools Act @ 20 Symposium held by the Optentia Research Entity on the Vaal Campus of the NorthWest University, Vanderbijlpark, 14 and 15 September. 